\title{
Contributions to High-Resolution Electron Microscopy by Gareth Thomas' NCEM
}

\author{
Michael A. O’Keefe \\ OKCS, 18528 Mesa Verde Way, Castro Valley, CA 94552, USA
}

Calls for a National Center for Electron Microscopy (NCEM) originated with three eminent electron microscopists: Gareth Thomas, John Cowley and Robert Glaser. Their 1970s proposals were for a center to advance electron microscopy science and provide a pool of advanced electron microscopes. The NCEM opened in 1983 and included a JEOL ARM-1000 with exceptional resolution of 1.6A.. To assist interpretation of ARM images, we set up an NCEM computer center using SHRLI [1] for image simulation and developed user-friendly software called TEMPaS for TEM Processing and Simulation [2], later renamed NCEMSS [3]. During his term as NCEM director, Gareth Thomas employed the ARM and NCEMSS to investigate advanced materials such as zeolites [4], ceramics [5], and metalmatrix composites [6]. To take materials characterization beyond the $1.6 \AA$ resolution limit of the ARM, we explored the use of images from several zone-axis directions to produce 3-dimensional maps (fig. 1a) [7], and extended the ARM resolution of $1.6 \AA$ (fig.1c) to $1.4 \AA$ using focal series (fig.1d) [8].

To advance beyond the ARM's $1.4 \AA$ information limit, I proposed an ambitious project worthy of Gareth's NCEM. Our staurolite work had earned a DOE commendation for outstanding research and I received funding for a new instrument that I named the One-Ångstrom Microscope (OÅM). I designed the OAM as a $300 \mathrm{keV}$ FEG TEM using improved beam coherence, very high magnification and a new 3 -fold stigmator to achieve sub-Ångstrom imaging down to 0.78 [9]. Following extensive discussions with potential manufacturers, I selected Philips (now FEI) to build the OAM. The OÅM enabled NCEM to once again push the performance envelope [10]. With YC Wang, I obtained the first TEM images to show atom columns $0.89 \AA$ apart in [110] diamond in 1999 (fig 2a) [11]. Analysis of our sub-Rayleigh resolution led me to a method of reliably deriving accurate atom positions from images (fig $2 \mathrm{~b}, \mathrm{c}$ ) [12]. I improved $\mathrm{O} \AA \mathrm{M}$ coherence (fig.2d) to reach its design resolution, showing atom columns $0.78 \AA$ apart in [112] silicon (fig.3) [13,14] and the first images of lithium atom columns [15]. Without Gareth Thomas, NCEM came to espouse nonsense science. Publications claimed that HRTEM images "do not show atom positions", Scherzer imaging "requires knowledge of atom species and positions", information limit is "not determined by coherence", and "Young's fringes determine information limit". The acme was a claim to have "extended information limit by developing software for focal series reconstruction". The environment established by Gareth Thomas's integrity and visionary leadership is sorely missed.

\section{References:}

[1] M.A. O'Keefe, P.R. Buseck and S. Iijima, Nature 274 (1978) p.322-324.

[2] M.A. O'Keefe, 45th Ann. Proc EMSA, Baltimore, Maryland (1987) p.364-365.

[3] Michael A. O'Keefe and Roar Kilaas (1989) < http://www.osti.gov/scitech/servlets/purl/5966936>

[4] R.S. Rai, M.A. O'Keefe and G. Thomas, 43rd Ann. Proc. EMSA, Louisville, KY (1985) p.372-373.

[5] T. Epicier, M.A. O'Keefe and G. Thomas, Acta Cryst. A46 (1990) p.948-962.

[6] V. Radmilovic, M. A. O'Keefe, and G. Thomas, Electron Microscopy 2 (1992) p.449-450.

[7] K.H. Downing, Hu Meisheng, Hans-Rudolf Wenk and M.A. O'Keefe, Nature 348 (1990) p.525-528.

[8] H.-R. Wenk, K.H. Downing, Hu Meisheng, and M.A. O'Keefe, Acta Cryst. A48 (1992) p.700-716.

[9] Michael A. O'Keefe (1992) < http://www.osti.gov/scitech/servlets/purl/6709988 >

[10] M.A. O'Keefe et al., Ultramicroscopy 89 (2001) 4: p.215-241.

[11] Y.C. Wang et al., Microscopy \& Microanalysis 5 (1999) 2: 822-823.

[12] M.A. O'Keefe, L.F. Allard and D.A. Blom, J. Electron Microscopy 54 (3) (2005) 169-180.

[13] M.A. O'Keefe, E.C. Nelson, Y.C. Wang, and A. Thust, Phil. Mag. B 81 (2001) 11: p.1861-1878.

[14] Michael A. O'Keefe, Ultramicroscopy 108 (2008) p.196-209, doi:10.1016/j.ultramic.2007.07.009

[15] Yang Shao-Horn et al., Nature Materials 2 (2003) p.464-467. 

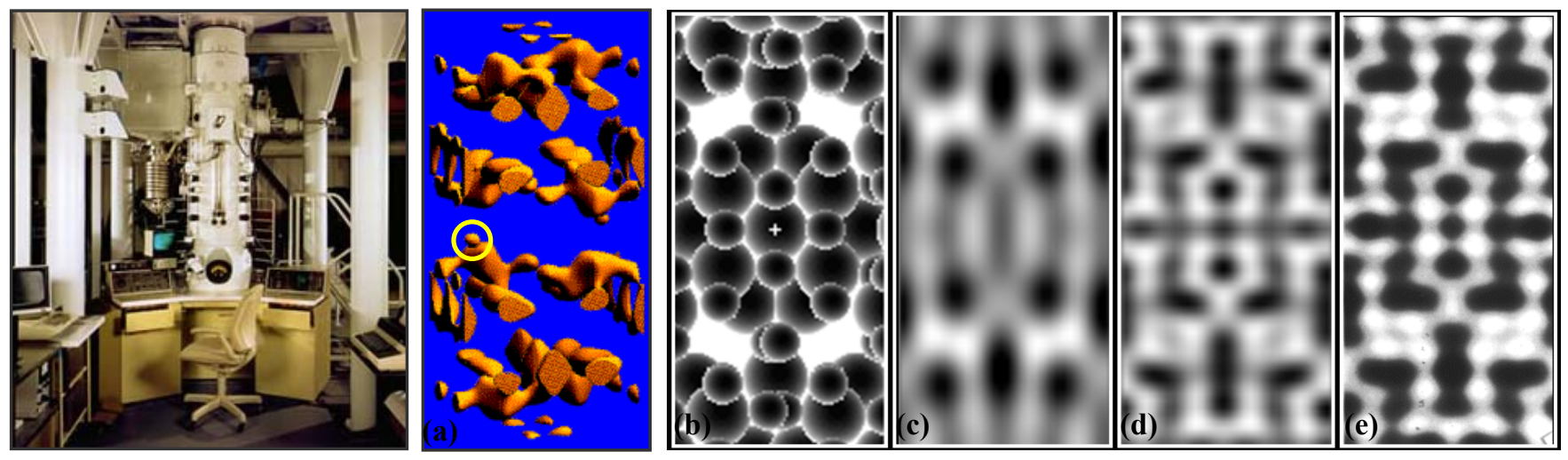

Figure 1. JEOL ARM-1000 (left). (a) 3D reconstruction of staurolite from ARM images in 5 different orientations shows presence of $\mathrm{O}$ atom (circled). (b) [001] model of staurolite. (c) Scherzer-focus ARM image at $1.6 \AA$ resolution. (d) Resolution of $1.4 \AA$ from focal-series is confirmed by $1.4 \AA$ simulation (e).
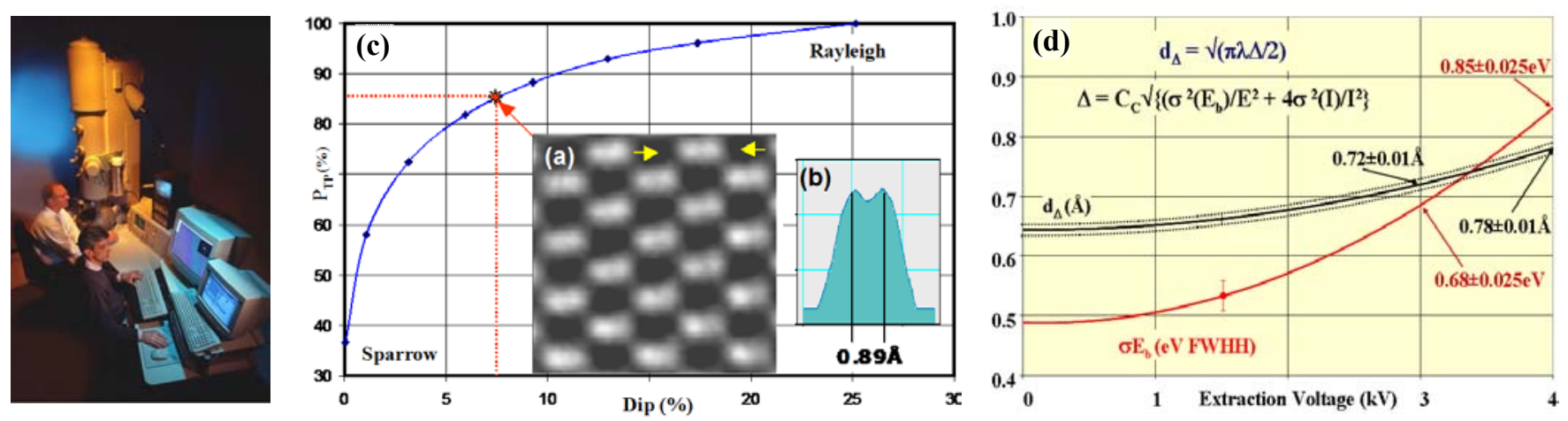

Figure 2. Philips CM300-OAM (left). OÅM image of [110] diamond (a) shows resolution of $\mathrm{C}$ atom columns $0.89 \AA$ apart. Profiling (b) reveals peak separation of $0.76 \AA$ due to sub-Rayleigh resolution as predicted by dip curve (c). Improvement in information limit $\mathrm{d}_{\Delta}$ from $0.78 \AA$ to $0.72 \AA$ was achieved by reducing FEG extraction voltage $\mathrm{E}_{\mathrm{b}}$ from $4 \mathrm{kV}$ to $3 \mathrm{kV}$ (d) to allow $0.78 \AA$ imaging of $\mathrm{Si}$ [112] (Fig.3b).
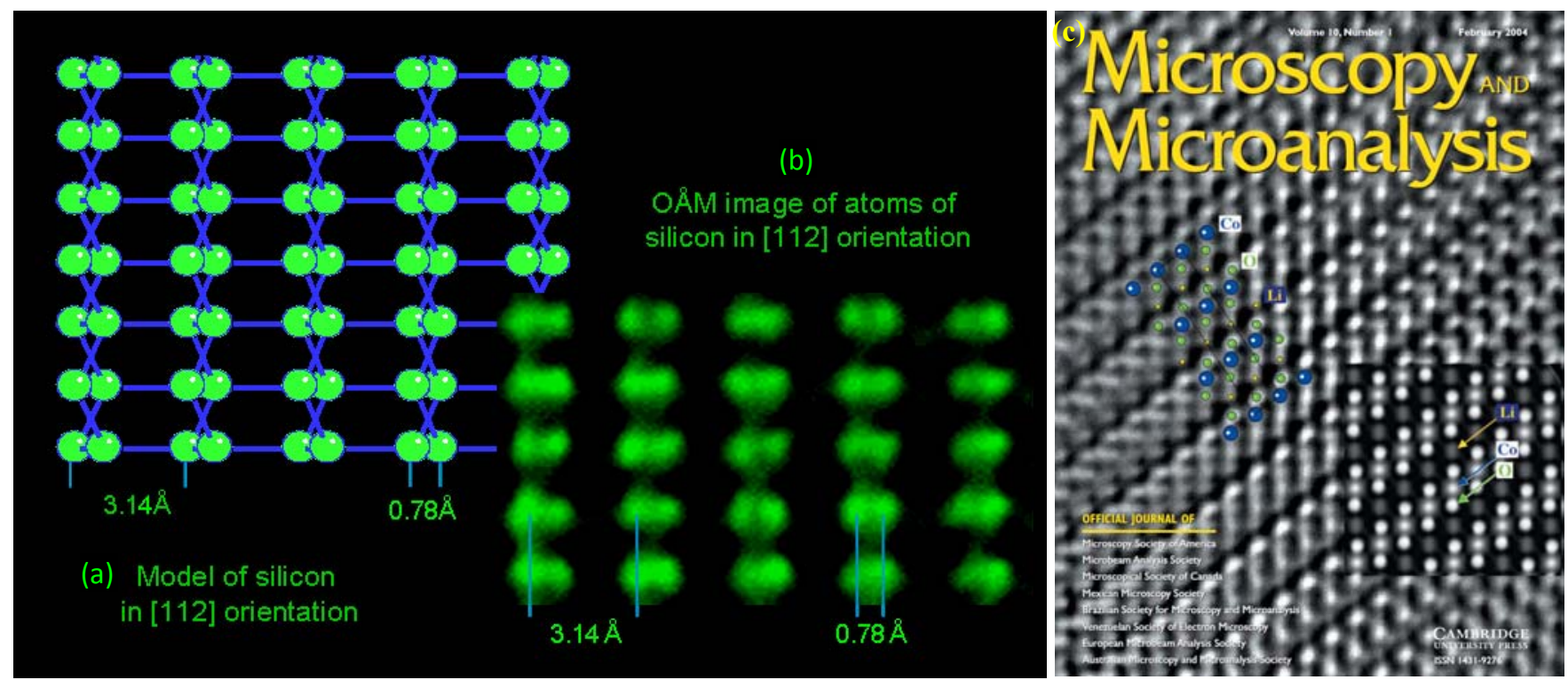

Figure 3. Model of silicon in [112] orientation (a). OÅM image shows resolution of Si atom columns separated by $0.78 \AA$ (b). OAM image of $\mathrm{LiCoO}_{2}$ (c) was the first HRTEM image to show Li atoms. 